\title{
Modeling of Common Rail System and Constant Volume Chamber in Biodiesel Combustion: A Review
}

\author{
Him Ramsy ${ }^{1, a}$, Amir Khalid ${ }^{1, b}$, Adiba Rhaodah Andsaler ${ }^{1}$, M. Jaat ${ }^{1}$ \\ ${ }^{1}$ Automotive Research Group (ARG), ${ }^{1}$ Centre for Energy and Industrial Environment Studies \\ (CEIES), Universiti Tun Hussein Onn Malaysia, Parit Raja, Batu Pahat, 86400 Johor, Malaysia \\ Email: ${ }^{2} m i \_j i e a 1 @ y a h o o . c o m,{ }^{b}$ amirk@uthm.edu.my
}

\begin{abstract}
Keywords: Rapid Compression Machine; Ignition Delay; Nozzle; Injection System; Air Motion; Ambient
\end{abstract}

\begin{abstract}
Among the challenges faced by diesel engines combustion nowadays are to reduce emission especially Nitrogen Oxide $\left(\mathrm{NO}_{\mathrm{x}}\right)$ and Particular Matter (PM) while enhancing fuel efficiency and power. The purpose of this review is to explore the mixture formation of biodiesel combustion using constant volume chamber and optical visualization. This paper reviewed the development of a single-shot combustion system and constant volume chamber. This review has shown that the application of Rapid Compression Machine (RCM) is used to simulate actual condition especially the injection pressure and air motion. The review also found that the mixing between fuel and air is unavoidable and very important during ignition delay period thus predominantly influences the exhaust emission. The detailed behavior of injection characteristic that strongly effects the mixture formation especially the spray evaporation and spray interference was discussed.
\end{abstract}

\section{Introduction}

The challenge for the diesel engine today is to reduce raw emission such as Nitrogen Oxide $\left(\mathrm{NO}_{\mathrm{x}}\right)$ and Particular Matter (PM). To meet this challenge, the mixture formation is indispensable to improve exhaust emission from diesel engine must be control especially fuel-air mixing at early of ignition process [1-5]. Various phenomena that involved in the diesel combustion, the physical factor plays a significant role in the ignition of diesel sprays and linked to the improvement of exhaust emission by fuel-air premixing. Furthermore some technique to reduce particulate emission was carried out, one of most promising is high pressure injection that able to the production engine gives remarkable improvement of particulate emission [6-8]. In this review, authors have started review to investigate the relation between injection pressure, injection timing and mixture formation. For this review, the focusing improvement mixture formation in delay ignition such as, ambient gas pressure, fuel system, pressure and temperature of air. The methodology of this review is using Rapid Compression Machine (RCM) with single-shot of common rail system.

Rapid Compression Machine (RCM) is used to simulate the diesel combustion in a combustion chamber over a wide range of ambient pressure and ambient temperature by varying the compression ratio. The high pressure and temperature can be yield through the RCM by method of a very light piston being shot by compressed air and rammed into a tapered stop ring [9]. At the end of the compression, the temperature and pressure can be differentiated by changing the starting position of the piston [10]. The decision made is to use a very light piston to obtain sufficient compression speed and strong impulse acting on the stopping device. On one side contains the base surface of the chamber, this chamber is composed of pyrex glass to enable observation of the spray and flame development [11]. When the piston motion induces air inside the chamber, a swirl connecting port was used to produce a swirl flow inside the chamber. The port inclination angle can control the swirl velocity where velocity at 2/3-location from chamber centre is defined as swirl velocity [12]. For the fuel injection system, an electronically controlled single-shot common rail injection system is employed to inject the fuel (biodiesel) into a combustion chamber. The time and amount of injected fuel is controlled by a fuel injection controller [13] as shown in Figure 1. 

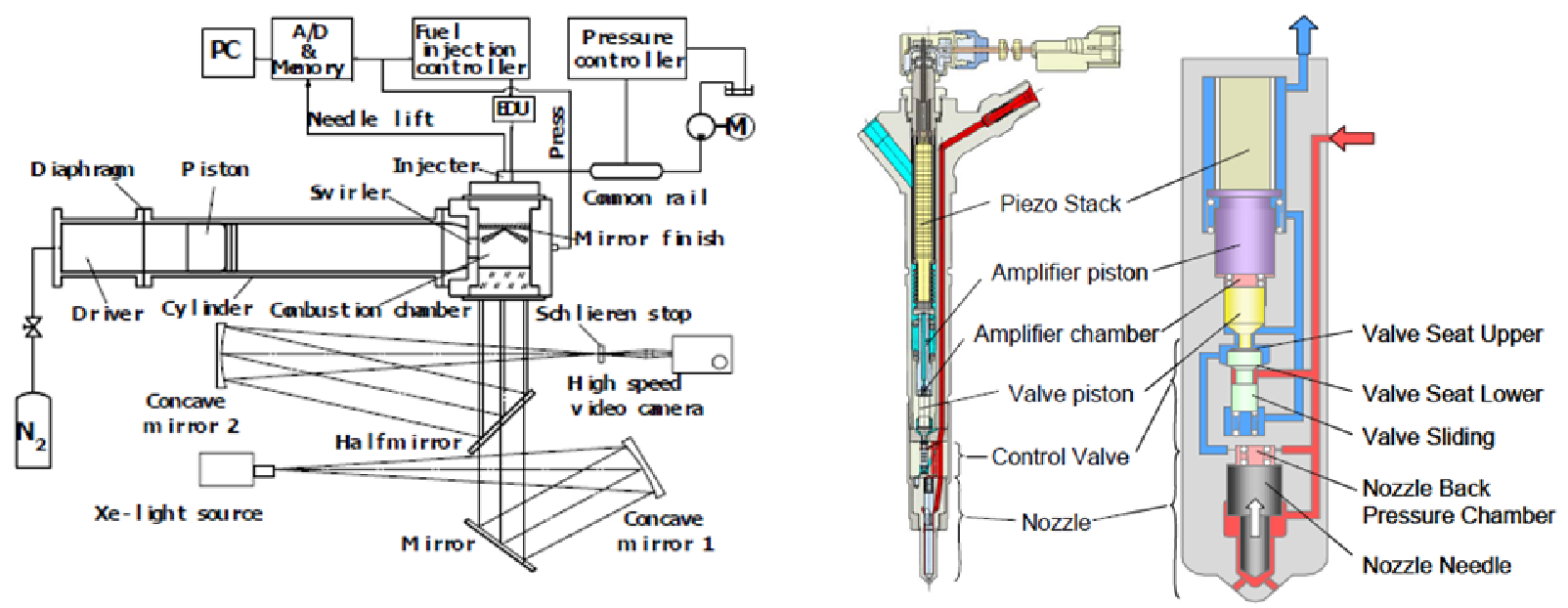

Figure 1: Schematic of RCM and Injection System [11] Figure 2: Model of Injector [15]

A single-shot common rail fuel injection system is used to inject the fuel into a combustion chamber. The common rail system can reduce exhaust emission such as $\mathrm{NO}_{\mathrm{x}}$ and $\mathrm{PM}$ simultaneously generating more engine power [14]. Figure 2 show the model of piezo injector, a comparison between second generation Common Rail System (CRS)-Piezo and solenoid fuel injectors that run reliably up to $180 \mathrm{MPa}$ while injecting precisely-measured fuel delivers up to 5 times per combustion cycle. The atomization can be improved through a combustion chamber which contributes to emission reduction by shortening the nozzle orifice diameter. Various particulate filters have been developed to reduce PM emission. The high injection pressure, clean burning, less soot loading occurs and thus smaller and less expensive particulate filters are the benefits of the reduction in PM emission [16,17].

Generally, high pressure injection results in smaller spray droplets and shorter injection periods. The well atomized spray shortens the ignition delay, activates combustion and reduces fuel consumption, smoke, Hydrocarbon (HC) and PM. It was commonly believed that the purpose of high injection pressure was the reduction of PM and the injection timing was retarded so as to reduce $\mathrm{NO}_{\mathrm{x}}[18]$. Figure 3 shows the combustion period decreased with retarded injection timing. The decreasing temperature due to the decrease of combustion period freezes the NO chemistry. As injection timing was retarded, the heat release rate curve showed that most of energy was released by pre-mixed combustion and only a small portion of the energy was released by diffusion controlled combustion. It is believed that the in-cylinder temperature is increased at retarded injection timing, but the increase in $\mathrm{NO}_{\mathrm{x}}$ is not observed due to the decrease of combustion period during the expansion process [19].
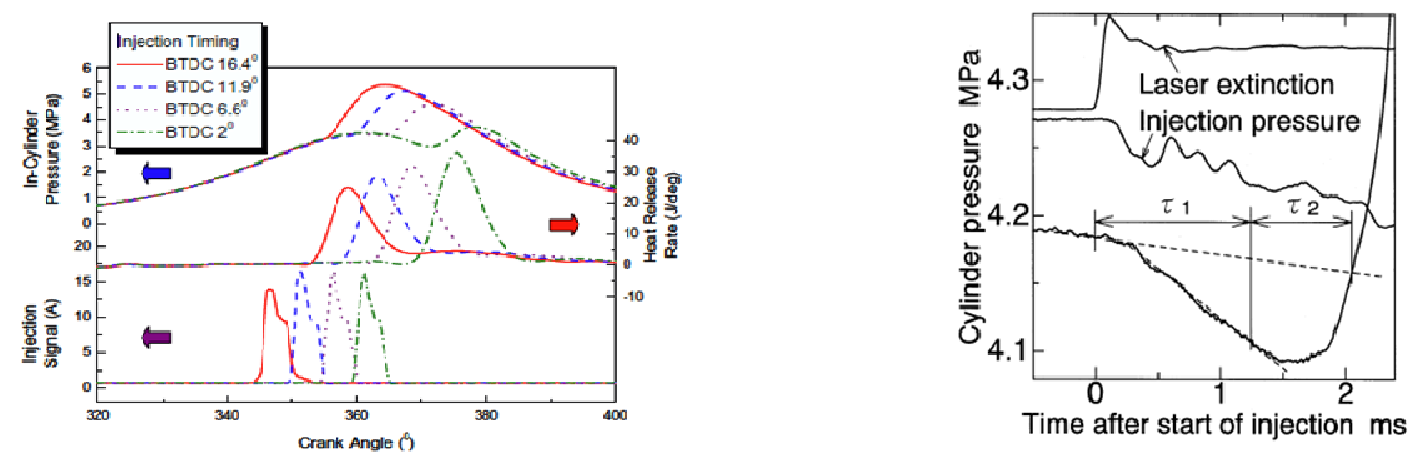

Figure 3: Effect of Injection Timing [17] Figure 4: Definition of the Ignition Delay [20]

Figure 4 shows the definition of ignition delay during the test in the RCM. Piston pressure and the definition ignition delay times $\tau_{1}$ and $\tau_{2}$. For $\tau_{1}$ is the period of time from the start of injection to when the piston pressure for a acting spray separates from that of an identical spray injected into an inert nitrogen atmosphere [20]. The period time from $\tau_{1}$ to continuous pressure 
curve cross the dated straight line is time $\tau_{2}$ that represents the heat loss from the combustion chamber. The combination from $\tau_{1}+\tau_{2}$ is defined as the ignition delay time that is used to characterize diesel fuel [21].

\section{Factor Effecting Ignition Delay in Diesel Combustion}

The factor effecting ignition delay is air pressure, the physical process such as fuel atomization and spray penetration. It directly influences ignition delay. When the temperature is higher, pressure almost gives no effect on $\tau_{1}$ while it has a great influence on $\tau_{2}$ because of larger droplets and lower fuel-air mixing rate as the pressure decreases by fact of fuel atomization is poor. Air temperature also governs ignition delay. Figure 5 shows measured pressure differences $P_{f}-P_{a}$ and $P_{f}-P_{n}$ versus time for temperature $T_{i}$ in which $\mathrm{t}$ is the time elapsed from starting injection. The early circular on reach curve of $P_{f}-P_{n}$ is net heat release and then the second is the pressure recovering time. The temperature of the non-injection cycle $P_{a}$, the nitrogen cycle $P_{n}$ and the fired cycle pressure $P_{f}$ were first studied with many initial temperature at an initial pressure of $\mathrm{P}_{\mathrm{i}}=3.8 \mathrm{MPa}$.

The cylinder pressure is traced during the ignition delay, at ambient temperature and ambient pressure reacting of 4.2, 8.0 and 12.0 MPa as shown in Figure 6. When the ambient temperature, $T_{a}$ and ambient pressure, $P_{a}$ increase the injection is started and the timing is rise with cylinder pressure increase steeply a short. The reason for such behavior is still unknown; when rapid pressure increases and becomes slower at temperature higher than $1000 \mathrm{~K}$ at higher $P_{a}$. The gradient of the Arrehenius curve at around $700 \mathrm{~K}$ changes $T_{a}$ and $P_{a}$ is increasing when the $\tau_{1}$ is shorted. From the review, the total time $\tau_{1}+\tau_{2}$ are longer than $\tau_{1}$ and is more pronounced in $\tau_{1}+\tau_{2}$ is approximately.

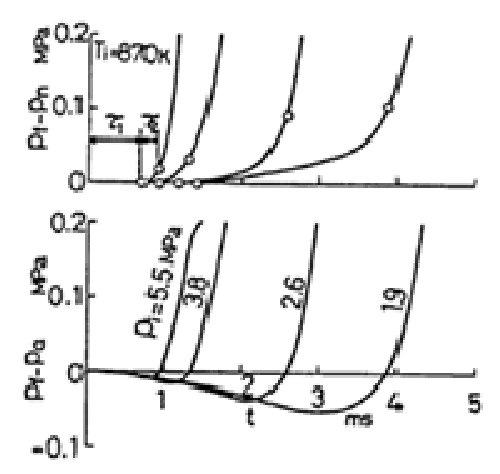

Figure 5: $p_{f}-p_{a}$ and $p_{f}-p_{n}$ versus time [10]
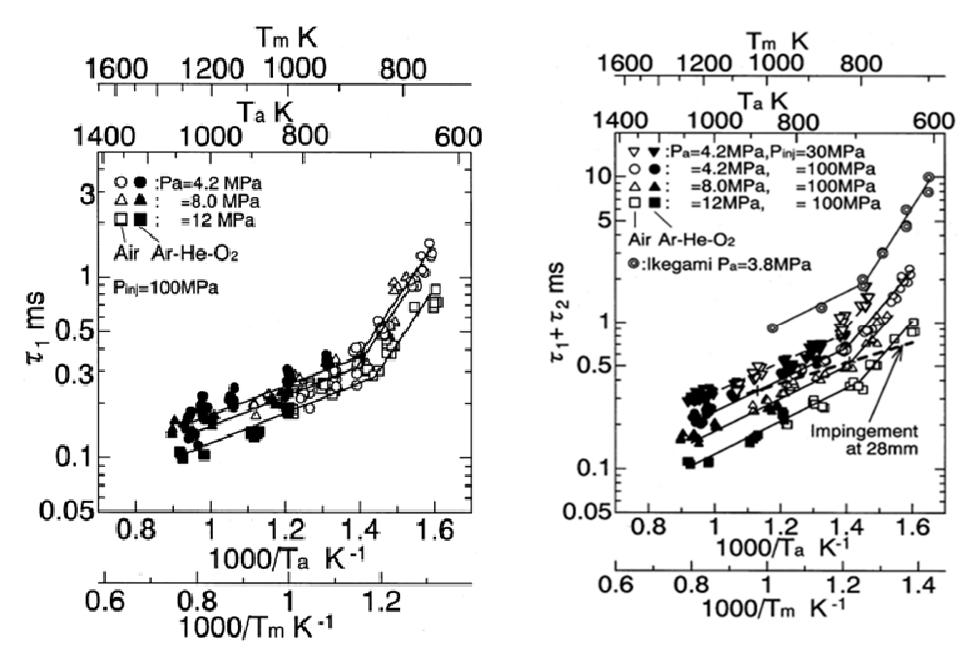

Figure 7: Effect of Ambient Pressure on Ignition Delay $\tau_{1}$ and $\tau_{1}+\tau_{2}[22]$

The lower injection of $30 \mathrm{MPa}$ and a $P_{a}$ of 4.2 MPa data from Arrehenius have been plotted as show in Figure 7. The injection of $14 \mathrm{MPa}$ and a $P_{a}$ of $3.8 \mathrm{MPa}$ are also plotted by Ikegami and Miwa [23] from their experiment data. The different injection pressure of 14, 30 and $100 \mathrm{MPa}$ was obtained from the data. It is very clear that varying increased injection pressure can shorten the ignition delay. The high injection pressure is because of the better mixing achievable [24]. The different types of injectors with different geometries, produces different amount of losses in fuel flow rate based on these different injectors [25,26]. Different types of injectors have different pattern nozzle, the nozzle concept is that after the closing of the nozzle in high pressure part of the combustion process, the fuel is stored in the injector holes. The temperature starts to increase the injector body because of the fuel expansion during the expansion stroke. Hence a liquid film is formed outside the holes at the nozzle tip. Furthermore, the fuel expanding out of the nozzle holes is adsorbed in the sooty deposit and reacts to increase deposit formation rate [27,28]. 


\section{Conclusion}

The review of this paper is to study and investigate the basic characteristics of combustion that strongly give effect on mixing composition and affect the ignition delay. Based on the review that was studied, the following conclusion can be made:

1. The pressure is dependent on the delay is lost at high pressure. High temperature is influenced the temperature that depend on ignition delay.

2. To reduce the Nitrogen Oxide $\left(\mathrm{NO}_{\mathrm{x}}\right)$ and Particulate Matter the injection timing should be retarded. The mixture formation during delay period large amount of combustible mixture is formed because of high injection pressure

\section{References}

[1] Adam, A., N. Inuki, Y. Kidoguchi, and K. Miwa, A Study Droplets Evaporating at Diesel Spray Boundary During Ignition Delay Period. SAE paper 2007-01-1893, JSAE 20077026, pp.1-11, 2007.

[2] Grimaldi, C.N., L. Postrioti, M. Battstoni, and F. Millo, Common Rail HSDI Diesel Engine Combustion and Emissions with Fossil / Bio-Derived Fuel Blends. SAE paper 2002-01-0865, pp.1-9, 2002.

[3] Hochhauser, A.M., Review of Prior Studies of Fuel Effects on Vehicle Emissions. SAE paper 2009-01-1181, SAE Int. J. Fuels Lubr. Vol. 2, Issue 1, pp.541-562, 2009.

[4] Tsuda, S., H. Kosaka, and T. Aizawa, A Study on Effect of Heterogeneity of Oxygen Concentration and Temperature Distributions in a Combustion Chamber on Combustion and Emission of Diesel Engine. JSME Int. Con. COMODIA DE3-2, pp.189-196, 2008.

[5] Baumgarten, C., Mixture Formation in Internal Combustion Engines, in Springer, Friedrichshfen, Germany. 2005.

[6] Johnson, T.V., Diesel Emission Control in Review. SAE Int. J. Fuels Lubr., Vol. 1, Issue 1, pp.68-80, 2008.

[7] Takahashi, H., K. Tomaru, S. Shiga, T. Karasawa, and T. Kurabayashi, Characteristics of Diesel Spray with Unsteady and Higher Injection Pressure Using a Rapid Compression Machine. SAE paper 910226, pp.1-8, 1991.

[8] Wen, T., G. Ebeling, M.A.O. Marques, and R. Streck, Injection Pressure on Diesel Engine Performance and Emission. SAE paper 921488E, pp.1-9, 1992.

[9] Khalid, A. and B. Manshoor, Analysis of Mixture Formation and Flame Development of Diesel Combustion Using a Rapid Compression Machine adn Optical Visualization Technique. Applied Mechanics and Materials Vols. 315(2013), Trans Tech Publications, Switzerland, pp.293-298, 2013.

[10] Miwa, K., T. Ohmija, and T. Nishitani, A Study of the Ignition Delay of Diesel Fuel Spray Using a Rapid Compression Machine. JSME Series II, Vol. 31, No. 1, pp. 166-173, 1988.

[11] Amir Khalid, Keisuke Hayashi, Yoshiyuki Kidoguchi , Tomoaki Yatsufusa, "Effect of air entrainment and oxygen concentration on endothermic and heat recovery process of diesel ignition”, (2011) SAE Technical Papers, DOI: 10.4271/2011-01-1834.

[12] Khalid, A. and B. Manshoor, Effect of High Swirl Velocity on Mixture Formation and Combustion Process of Diesel Spray. Applied Mechanics and Material Vols. 229-231, Trans Tech Publications, Switzerland, pp.700-704, 2012.

[13] Ikegami, M., K. Miwa, and X.-h. LI, Spray Process and Fuel Pyrolysis in the Initial Stage of Diesel Combustion. JSME, Vol. 29, No. 253, pp.2189-2196, 1986.

[14] Ikagemi, M., K. Miwa, and M. Inada, A Study on Ignition and Combustion of a Diesel Spray by Mean of a Rapid Compression Machine. JSME, Vol. 24, No. 195, pp.1608-1615, 1981.

[15] Dingle, P.J.G. and M.-C.D. Lai, Diesel Common Rail and Advanced Fuel Injection Systems. SAE International No. T-117, pp.24, 2005.

[16] Oki, M., S. Matsumoto, Y. Toyoshima, K. Ishisaka, and N. Tsuzuki, 180MPa Piezo Common Rail System. SAE paper 2006-01-0274, pp.1-8, 2006. 
[17] Park, C., S. Kook, and C. Bae, Effect of Multiple Injections in a HSDI Diesel Engine Equipped with Common Rail Injection System. No. 724, 2004.

[18] Kimura, S., H. Ogawa, Y. Matsui, and Y. Enomoto, An Experimental Analysis of LowTemperature and Premixed Combustion for Simultaneous Reduction of $N_{x}$ and Particulate Emission in Direct Injection Diesel Engines. Int. J. Engine Research. Vol. 3, No. 4, pp.249259, 2002.

[19] Tonini, S., M. Gavaises, C. Arcoumanis, and A. Theodorakakos, Prediction of Luquid and Vapor Penetration of High Pressure Diesel Sprays. SAE paper 2006-01-0242

[20] Ishiyama, T., K. Miwa, and O. Horikoshi, A Study on Ignition Process of Diesel Spray. JSME Int. J. Series B, Vol. 38, No. 3, pp.483-489, 1995.

[21] Kee, S.-S., A. Mohammadi, H. Hirano, Y. Kidoguchi, and K. Miwa, Experimental Study on Combustion Characteristics and Emissions Reduction of Emulsified Fuels in Diesel Combustion Using a Rapid Compression Machine. SAE paper 2003-01-1792, JSAE 20030042, pp.1-8, 2003.

[22] Khalid, A., Effect of Ambient Temperature and Oxygen Concentration on Ignition and Combustion Process of Diesel Spray. Asian Journal of Science Research, pp.1-11, 2013.

[23] Ikagemi, M. and K. Miwa, Ignition of Diesel Fuel Spray. J. Soc. Auto. Eng. Jpn., Vol. 36, No. 4, pp.352, 1982.

[24] Kobori, S., T. Kamimoto, and A.A. Aradi, A Study of Ignition Delay of Diesel Fuel Sprays. Int. J. Engine Research. Vol. 1, No. 1, pp.29-40, 1999.

[25] Argueyrolle, B., S. Dehoux, P. Gastaldi, L. Grosjean, F. Levy, A. Michel, and D. Passerel, Influence of Injector Nozzle Design and Cavitation on Coking Phenomenom. SAE paper 2007-01-1896, JSAE 20077184, 2007.

[26] Khalid, A., S.A. Osman, M. Jaat, N. Mustaffa, S.M. Basharie, and B. Manshoor, Performance and Emissions Characterisitcs of Diesel Engine Fuelled by Biodiesel Derived from Palm Oil. Applied Mechanics and Materials Vols. 315(2013), Trans Tech Publications, Switzerland, pp.517-522, 2013.

[27] Birgel, A., N. Ladommatos, P. Aleiferis, S. Zulch, N. Milovanovic, V. Lafon, A. Orlovic, P. Lacey, and P. Richards, Deposit Formation in the Holes of Diesel Injector Nozzles: A Critical Review. SAE paper 2008-01-2383, pp.1-12, 2008.

[28] Blessing, M., G. König, C. Krüger, U. Michels, and V. Schwarz, Analysis of Flow and Cavitation Phenomena in Diesel Injection Nozzles and Its Effects on Spray and Mixture Formation. SAE paper 2003-01-1358, pp.1-13, 2003. 